\title{
A Numerical Method Using VAMPIRE Modelling for Prediction of Turnout Curve Wheel-rail Wear
}

\author{
Y. Sun ${ }^{*}$, C. Cole ${ }^{1}$ and Paul Boyd ${ }^{2}$ \\ ${ }^{1} \mathrm{CRC}$ for Rail Innovation Australia \\ ${ }^{2}$ Centre for Railway Engineering, CQ University, Australia \\ *E-mail: y.q.sun@,cqu.edu.au
}

\begin{abstract}
A numerical method using VAMPIRE modeling for the dynamic performance of a wagon passing through a turnout is present with special concern of wheel-rail wear. The objective is to investigate the potential benefit of operation strategy with respect to minimising wheel-rail wear. The simulation shows that the travel speed significantly affects the wheel-rail wear for passing the turnout.
\end{abstract}

\section{INTRODUCTION}

Railway turnouts are generally sharper than curves in plain track, and hence increase vehicle dynamics. There is typically no transition or superelevation. Turnout curves produce a rapid change in the wheelset direction and bogie twisting position. Turnout crossing may also provoke successive rapid changes to the wheelset, bogie, and vehicle orientation. The outcome of such an event may cause the plastic flow at the nose of crossing, rolling contact fatigue (RCF) defects in track components and may lead to wear failure in turnout curves and crossings.

The dynamic interaction between rail vehicle and turnout has attracted the attention of railway researchers. Several methods have been developed to simulate the dynamic behavior when a vehicle passes through a turnout. The commercial multi-body system software, GENSYS was used to model the dynamic interaction between railway vehicle and turnout $[1,4]$ and the simulation results were validated through full-scale field testing [2]. A finite element (FE) model of a standard turnout design, a complex-valued modal superposition of track dynamics [3] is applied using the first 500 eigenmodes of the turnout model. It is shown that modes with eigenfrequencies up to at least $200 \mathrm{~Hz}$ have a significant influence on the magnitudes of the wheelrail contact forces. The multibody simulation package SIMPACK was used to calculate the vehicle dynamic behaviour due to passing a turnout $[5,6]$. The so-called strip method family in which the rail is partitioned into narrow strips was used to determine the wheel-rail contact forces in a turnout with the help of the semiHertzian method to model the wheel-rail contact [7]. Several Bernoulli-Euler beams were adopted in the turnout model to simulate the rails in the turnout zone in accordance with the turnout structure specification [8]. The flexible track model and the real-time wheel-rail penetration contact model in NUCARS were used for a tread bearing diamond crossing design study [9]. The turnout is described by a linear finite element model with modal damping in order to investigate vertical dynamics [10].

In our study on the dynamic interaction between rail vehicle and turnout, a method has been developed using VAMPIRE package. The contact issue of wheel-rail at a fixed crossing is the only parameter considered in this investigation. The wheel-rail wear in turnout curve section due to vehicle-turnout dynamic interactions is specially presented in this paper. The determination of wheel-rail wear due to a rail vehicle passing through a turnout follows the below steps:

- $\quad$ Step 1 - A vehicle model passes through the turnout without consideration of crossing. The entrance of turnout is assumed to be smooth. The purpose for this simulation is to determine the wheel-rail contact point.

- Step 2 - An algorithm that determines the contact points for a wheelset to pass the crossing is developed and applied for wheel-rail contact calculation. From the calculation in this step, it is found that the left wheel contact point in the first step has a dip movement when the left wheel passes through the crossing. The dip profile is considered as the track top surface irregularity at the crossing nose location.

- $\quad$ Step 3 - The simulations are carried out again to determine the wheel-rail wear numbers.

\section{VEHICLE-TURNOUT MODELING}

This section presents the wagon modelling and the track modelling.

\subsection{Vehicle Modeling}

A widely used container wagon with 92 tonne gross mass and ride control bogies is used for vehicle modeling using VAMPIRE software. The wagon 
modeling contains 11 masses (1 wagon car body, 2 bolsters, 4 sideframes, and 4 wheelsets). The connections among these 11 masses have been modeled using 17 stiffness elements, 74 bumpstop elements, 13 viscous damper elements, 116 friction elements, and 4 shear spring elements, which fully consider the nonlinear characteristics among connections. Fig. I shows the wagon modeling.

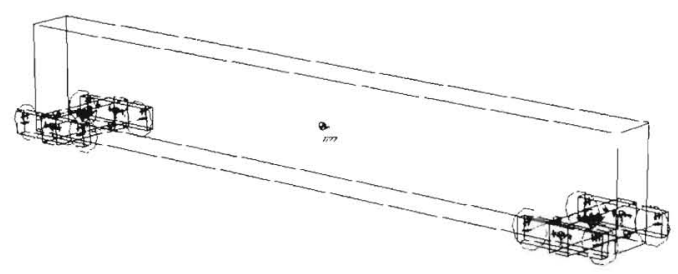

Fig. 1 Wagon Modeling

The wagon data for VAMPIRE wagon modeling are given in Appendix I.

\subsection{Wheel-Rail Modeling}

Wheel and rail profiles used for the wheel-rail contact parameter determination using VAMPIRE software are shown in Fig. 2 (a) and (b).

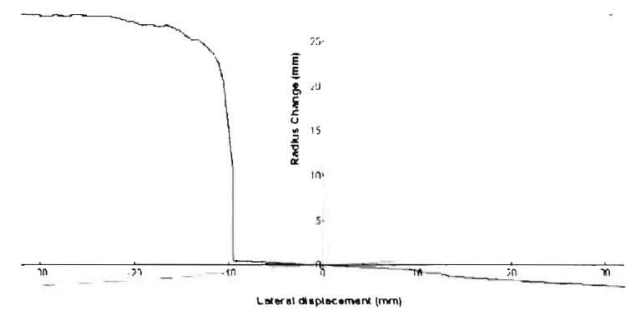

(a) Radius change

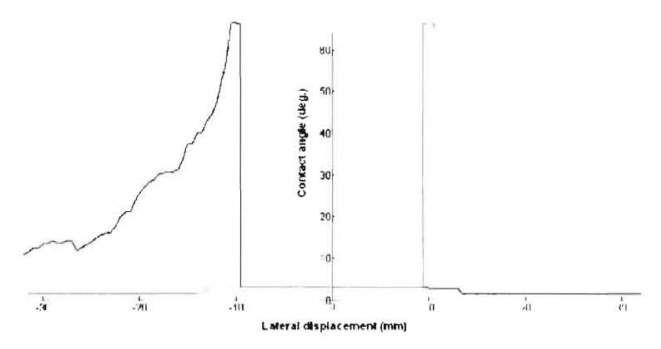

(b) Contact angle

Fig. 2 Contact parameters

\subsection{Turnout Modeling}

The standard design for a turnout with crossing rate 1:9 shown in Fig. 3 (a), is used for track modeling. The track length before the turnout is chosen as $30 \mathrm{~m}$, and the turnout length is about $26.3 \mathrm{~m}$, and the total length of track modeling is $120 \mathrm{~m}$. As there is no transition length for the curve with radius of $190 \mathrm{~m}$, the curvature is suddenly changed from zero to $5.26 \mathrm{radians} / \mathrm{km}$ from the straight line to the curve as shown in Fig. 3 (b).

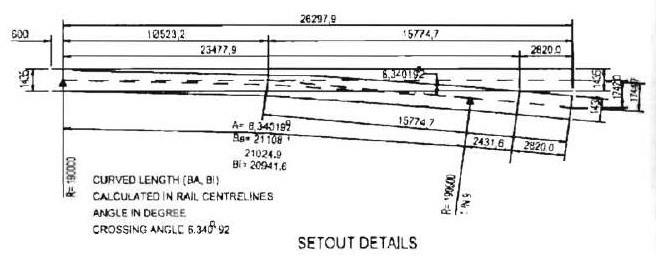

(a) Turnout with Crossing Rate 1:9

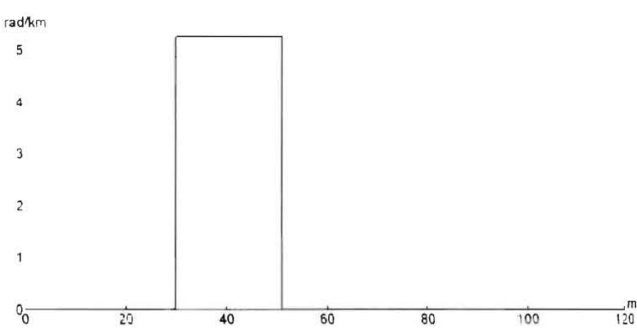

(b) Track Curvature

Fig. 3 Track Modeling

\subsection{Simulation without Consideration of Crossing}

The simulations have been conducted within the speed range 5 to $80 \mathrm{~km} / \mathrm{h}$. The track curvature in Fig. 3 (b) is taken as track design file input. As there is no superelevation and transition designed into the turnout, it has been found that even at a very low speed (e.g. $5 \mathrm{~km} / \mathrm{h}$ ), the left wheels (running towards the crossing nose) always have flange contact with the switch rail as shown in Fig. 4.

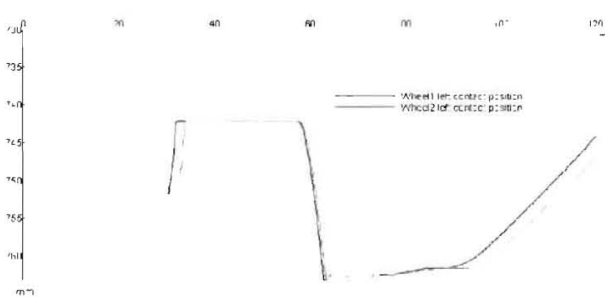

(a) Left wheel

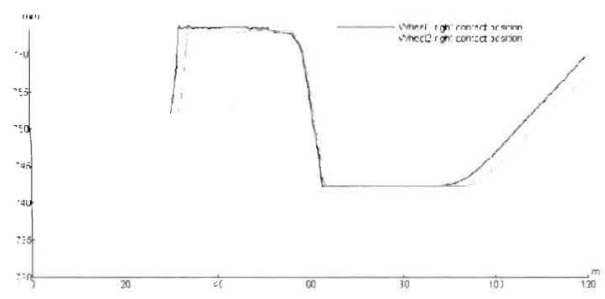


(b) Right wheel

Fig. 4 Wheel Contact Positions

From Fig. 4 (a), it can be seen that from the travel distance of $30 \mathrm{~m}$ the left wheels have a constant shift with about $9.5 \mathrm{~mm}$, which is the turning point for the wheel flange contact as shown in Fig. 2.

\section{TURNOUT CROSSING CONTACT MODELING}

Consider a wheel running towards the crossing nose. As the gap (Fig. 5) in the throat of the crossing widens due to wing rail heeling in a different direction (from heel point (HP) on the wing rail), the wheel-rail contact point moves out to the field side of the wheel. The wheel continues to move to the field side until it encounters the nose of the crossing, which starts from the virtual point.

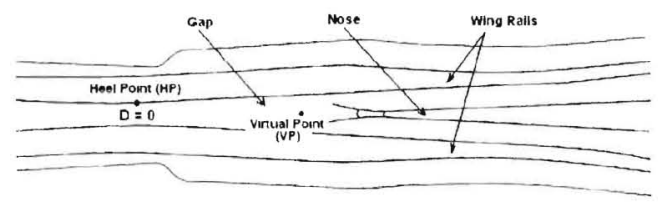

Fig. 5 A Typical Fixed V Crossing

\subsection{Nose Structure}

The nose structure of the crossing is shown in Fig. 6. The nose ramps upwards from the nose tip (virtual point). There is a transfer of contact from the wing rail to the nose. If the vehicle is travelling in the trailing direction, the process is reversed.
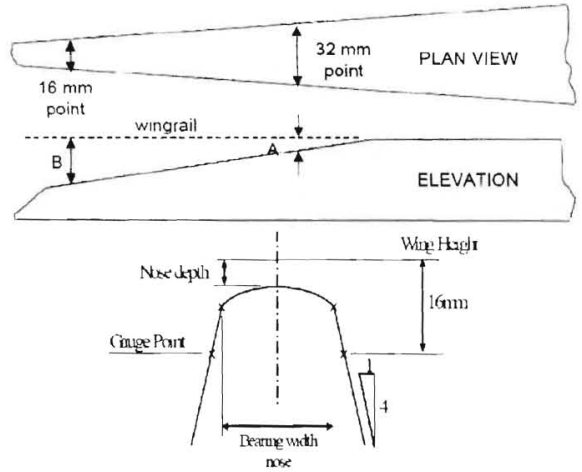

Fig. 6 Nose Structure

From Fig. 6, it can be seen that for the longitudinal profile of the nose there is a smooth transition curve.

\subsection{Wheelset-Crossing Contact}

The size and location of wheelset-crossing contact patch is mainly affected by the profiles of wheel tread, flange, railhead and nose. The parameters that affect the contact patches between the left wheel and the wing rail and/or the nose, and the right wheel and the stock rail, include the location of the contact points, the contact angles, the radii of the left wheel and the right wheel at the contact points.

An algorithm for evaluating the contact parameters of wheelset-crossing is introduced as a function of wheelset lateral displacement. The influence of wheelset yaw or attack angle is ignored. The flowchart shown in Fig. 7 outlines the steps taken in executing the calculations.

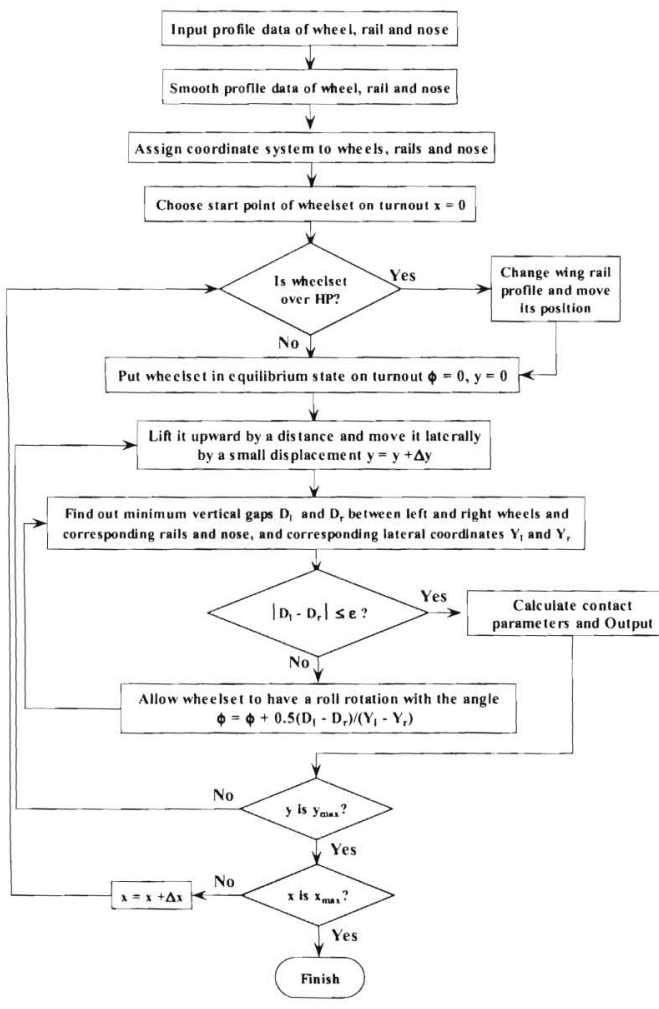

Fig. 7 Flowchart

Contact Calculation between Wheelset and Crossing Nose

The wheel and rail profiles in Section 2.2 are implemented in the calculation. The wheelset starts to move at the heel point $(D=0 \mathrm{~mm})$ as shown in Fig. 5 and runs towards the crossing nose until $\mathrm{D}=740 \mathrm{~mm}$. The wheelset is fixed at the left side with the lateral displacement $9.5 \mathrm{~mm}$ from the equilibrium position $(\mathrm{y}=$ $0)$.

Fig. 8 shows the left and right wheel-rail contact at the start point $\mathrm{D}=0$. For the left contact point (red point in the figure), it will gradually go down as the wheelset moves forward and the left wheel edge contacts the wing rail. When the left wheel touches the crossing nose surface and separates with the wing rail, it will go up as the left wheel runs up on the slope of nose and finally 


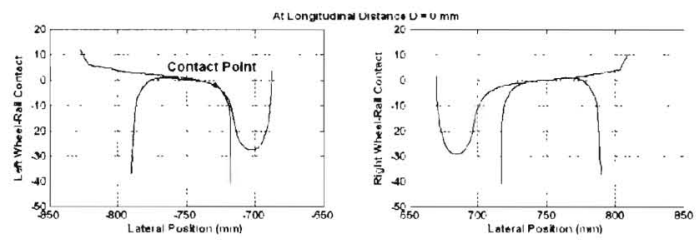

Fig. 8 Left and Right Wheel-Rail Contact

Fig. 9 shows the left and right wheel-rail contact at the different distance.
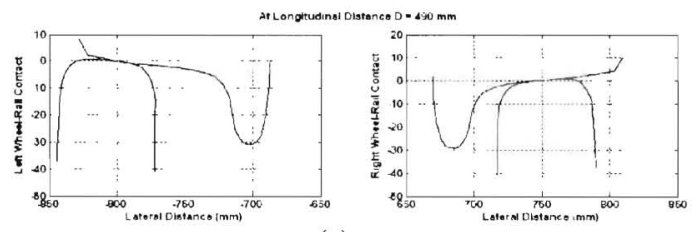

(a)

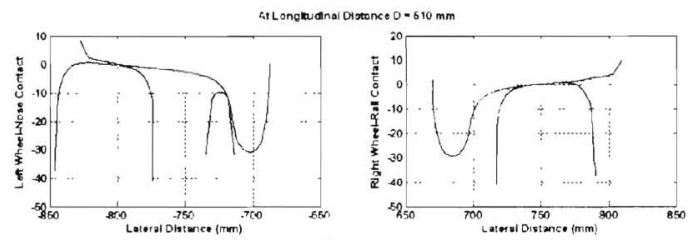

(b)

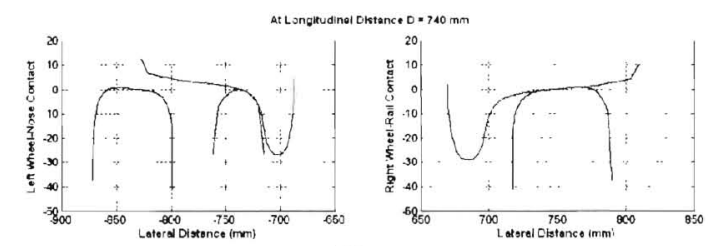

(d)

Fig. 9 Left and Right Wheel-Rail Contact at Several Distances

It is illustrated in Fig. 9 (b) that at the distance D = $510 \mathrm{~mm}$, the left wheel begins flange contact with the crossing nose and separation with the wing rail. The vertical movement of the contact point in Fig. 8 can be measured as the function of wheelset's longitudinal displacement, as shown in Fig. 10.

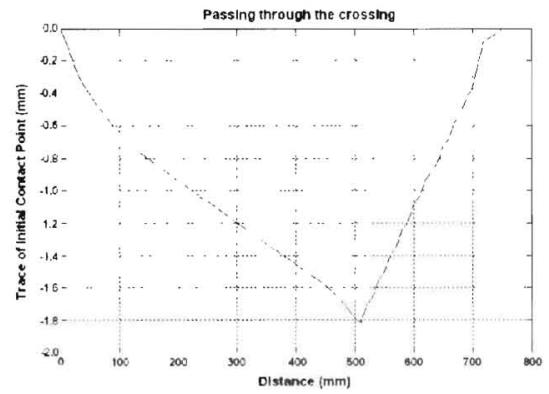

Fig. 10 Trace of Contact Point

\section{WHEEL-RAIL WEAR MODELING}

A limited number of wheel-rail wear models have been developed to predict the wheel-rail wear. A detailed literature review has been undertaken on the deterioration mechanisms in the wheel-rail interface with focus on wear prediction [11]. Another detailed review on wheel-rail wear models or 'wear indices' has been given [12], in which two main theories were proposed, one is Archard's wear law that wear is proportional to the normal load and the sliding distance. The other approach is the assumption that the volume of removed material is proportional to the frictional work (or the energy dissipated) developed in the contact patch. The frictional work per metre rolled distance is calculated as a sum of products containing the tangential forces, tangential spin moment and the corresponding creepages in the wheel-rail contact. The train resistance $F_{X}$ was used as an indicator of wheel-rail wear, which takes into account only the rolling resistance [13].

The wear number $\left(T_{\gamma}\right)$ used in VAMPIRE package is defined as a measure of the energy expended by the creep forces at the contact point. The energy in each of the longitudinal and lateral directions is obtained from the product of the creep force and creepage. The sum for the two directions is calculated as shown in Equation (1). The product of spin moment and spin creepage has not been considered in the calculation.

The wear number:

$$
\mathrm{T}_{\boldsymbol{\gamma}}=\mathrm{F}_{\mathrm{cx}} \xi_{\mathrm{x}}+\mathrm{F}_{\mathrm{cy}} \xi_{\mathrm{y}}
$$

where $\mathrm{F}_{\mathrm{cx}}$ and $\mathrm{F}_{\mathrm{cy}}$ are respectively the creep forces at longitudinal and lateral directions, $\xi_{\mathrm{x}}$ and $\xi_{\mathrm{y}}$ are the corresponding creepages.

\section{SIMULATIONS}

When analysing a crossing it is assumed that the left wheel contact point undergoes a dip as shown in Fig. 10. This dip is considered as the top surface irregularity on the left wing rail at the crossing position.

The wear numbers at the left and right wheel tread contacts and at flange contact point are plotted in Fig. 11,12 and 13 for wagon travel through the turnout at the different speeds.

Fig. 11 (a), (b) and (c) show the wear numbers at the left and right wheel tread contacts and at flange contact point at the speed of $30 \mathrm{~km} / \mathrm{h}$. 


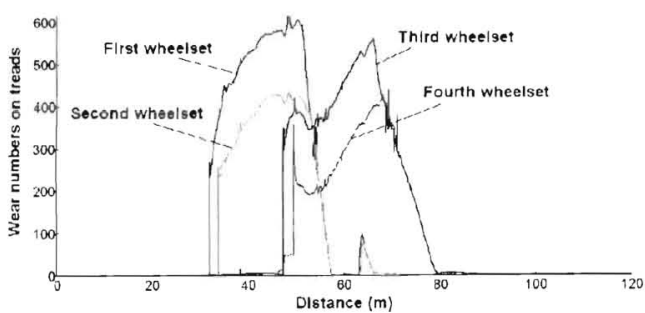

(a) Left wheels

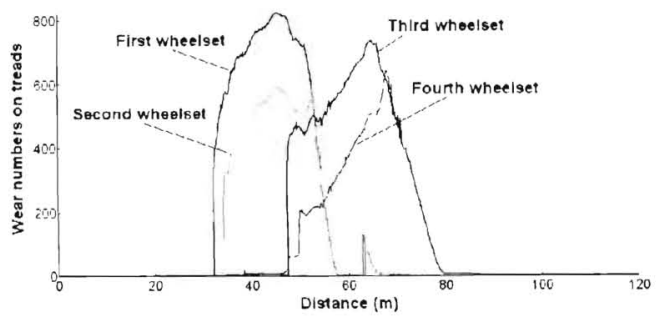

(b) Right wheels

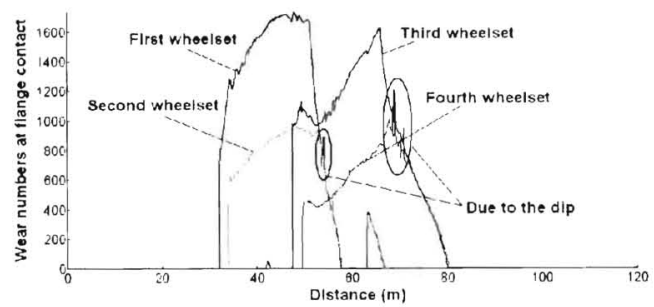

(c) Flange contact points

Fig. 11 Wear numbers at $30 \mathrm{~km} / \mathrm{h}$

From Fig. 11, it can be seen that the leading wheelset in a bogie plays main role in the wheel-rail wear for passing the turnout, and that two bogies have similar effect on the wheel-rail wear. The left wheel-rail wear includes the wheel flange and tread wear (or the corresponding rail corner and table wear) Fig. 11 (c) and (a), with the flange wear being about 3 times as much as the tread wear. The right wheel-rail wear is only the wheel tread wear (or the rail table wear), and its amount is larger than that of the left wheel tread wear.

In Fig. 11 (c), the small rapid changes, which are circled, are due to the dip shown in Fig. 10, which is assumed to occur due to the wheel passing over the crossing. It can be seen that the effect of the crossing on the wheel-rail wear is not significant and can be ignored comparing the effect of turnout curve section without transition and superelevation. It can be noted from Fig. 11 that the wheel-rail wear at the end section of turnout curve is severer than that at the start section if the vehicle travels from the point area.

Fig. 12 and Fig. 13 illustrate the comparison of wear numbers on the first and the third wheelsets at the speeds of 20,50 and $80 \mathrm{~km} / \mathrm{h}$.

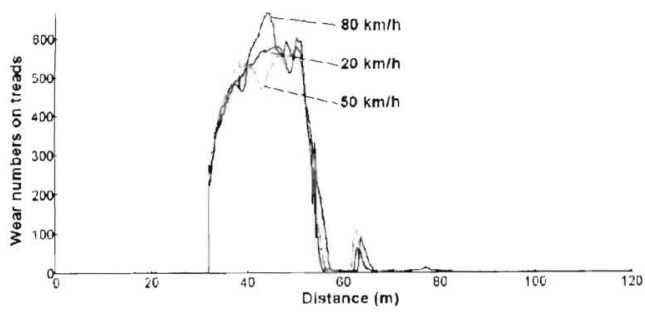

(a) Left wheels

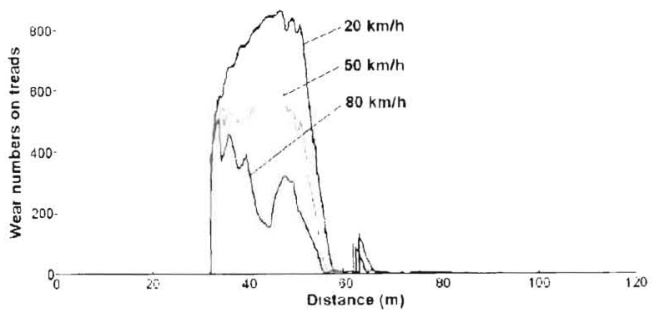

(b) Right wheels

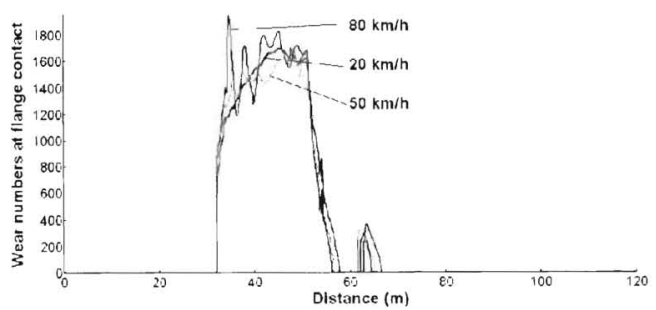

(c) Flange contact points

Fig. 12 The first wheelset

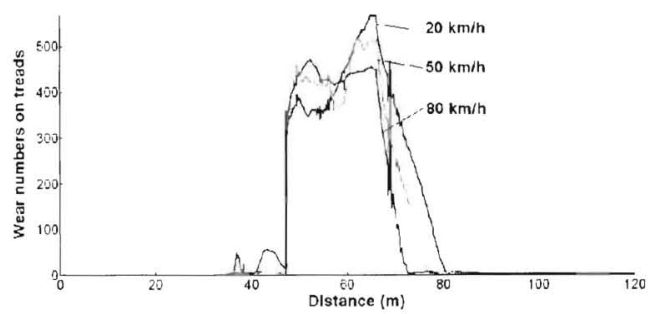

(a) Left wheels

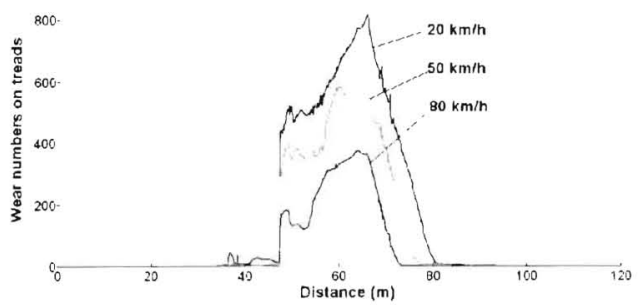

(b) Right wheels 


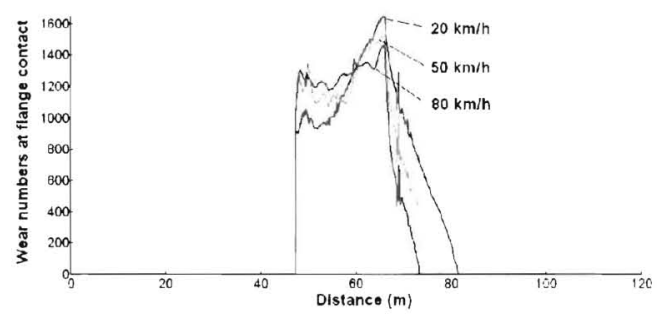

(c) Flange contact points

Fig. 13 The third wheelset

The reason that the wear numbers on the first and the third wheelsets are shown is that the wear numbers on the second and the fourth wheelsets are similar to those on the corresponding first and third wheelsets respectively; however their values are much smaller. From Fig. 12 (a), (b) and (c) for the leading bogie, at a higher speed $($ e.g. $80 \mathrm{~km} / \mathrm{h})$, it can be seen that the wheel-rail wear at the start section of turnout curve is slightly more severe than that at the end section. As the speed increases, the wear number on the right wheel tread contact is significantly reduced. From Fig. 13 (a), (b) and (c) for the trailing bogie, as the speed increases, the wheel-rail wear at the end section of turnout curve is still more severe than that at the start section. The wear number on the right wheel tread contact is also significantly reduced.

Should the maximum values of wear numbers on all left and right wheel treads and flanges be taken for further discussion, Fig. 14 shows the relationship between the maximum wear numbers and the speeds.

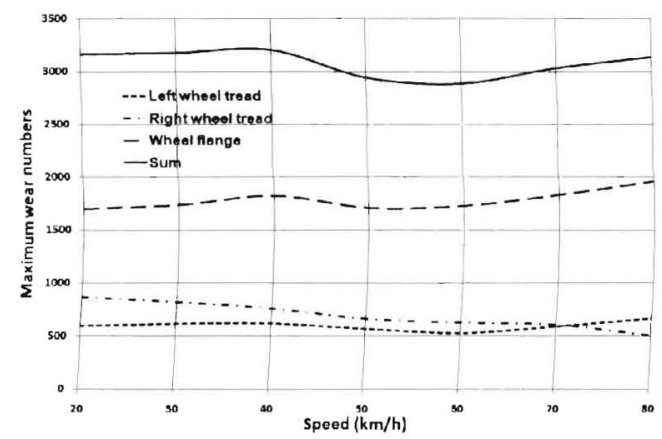

Fig. 14 The maximum wear number

In Fig. 14, the legend "Sum" is the sum of the maximum wear numbers of wheel flange, left and right wheel treads plotted over speed. It can be seen that as the speed increase the maximum wear number of the right wheel tread continues to decrease, however the maximum wear numbers of wheel flange and left wheel tread change differently, with the lowest value within the speeds of $50 \sim 60 \mathrm{~km} / \mathrm{h}$. For the sum value, it also has the minimum within the speeds of $50 \sim 60 \mathrm{~km} / \mathrm{h}$. For example, at the speed of $60 \mathrm{~km} / \mathrm{h}$, the lowest sum is
2884.5 while at the speed of $40 \mathrm{~km} / \mathrm{h}$, the highest sum is 3206.4 , and the increase is $11.2 \%$. This suggests that the speed within $50 \sim 60 \mathrm{~km} / \mathrm{h}$ is the optimal while the speed of around $40 \mathrm{~km} / \mathrm{h}$ is the worst case for the wheel-rail wear.

\section{CONCLUSIONS}

A method to investigate the wheel-rail wear of a turnout curve due to vehicle's passing a turnout has been developed using VAMPIRE modeling.

The relationship between the wheel-rail wear of the turnout curve and the travel speed is examined. The simulations show that for the leading bogie, at the speeds (e.g., less than $60 \mathrm{~km} / \mathrm{h}$ ) the wheel-rail wear at the end section of turnout curve is more severe than that at the start section. However, at the higher speed, the leading bogie causes the inverse situation. Independent of the speed, the trailing bogie will always cause the wheel-rail wear at the end section of turnout curve to be more severe than that at the start section.

In terms of the sum of the maximum wear numbers, the speed within $50 \sim 60 \mathrm{~km} / \mathrm{h}$ is the best to mitigate the wheel-rail wear for passing through the turnout.

\section{Acknowledgments}

Rail CRC Innovation Australia financially supported this research via a Rail CRC project granted to the first author. The support, involvement and encouragement of the colleagues of the Centre for Railway Engineering and the fellows of RailCorp, NSW are thankfully acknowledged.

\section{Reference}

[1]. KASSA, E. and NIELSEN J. C. O., 2008. Stochastic analysis of dynamic interaction between train and railway turnout. Vehicle System Dynamics, Vol. 46, No. 5, 429-449.

[2]. KASSA, E. and NIELSEN J. C. O., 2008. Dynamic interaction between train and railway turnout: full-scale field test and validation of simulation models. Vehicle System Dynamic's, Vol. 46, No. 5, 521-534.

[3]. KASSA, E. and NIELSEN J. C. O., 2008. Dynamic train-turnout interaction in an extended frequency range using a detailed model of track dynamics. JOURNAL OF SOUND AND VIBRATION.

[4]. KASSA, E., ANDERSSON, C. and NIELSEN J. C. O., 2006. Simulation of dynamic interaction between train and railway turnout. Vehicle System Dynamics, Vol. 44, No. 3, March 2006, 247-258.

[5]. SCHUPP, G., WEIDEMANN, C., and MAUER, L., 2004. Modelling the Contact between Wheel and Rail within Multibody System Simulation. Vehicle System Dynamics, Vol. 4l, No. 5, pp. 349-364.

[6]. SCHUPP, G., 2003. Simulation of Railway Vehicles: Necessities and Applications. 
MECHANICS BASED DESIGN OF STRUCTURES AND MACHINES, Vol. 31, No. 3, pp. 297-314.

[7]. SEBES, M., AyASSE, J. B., ChOllet, H., POULIGNY, P. and PIRAT, B., 2006. Application of a semi-Hertzian method to the simulation of vehicles in high-speed switches. Vehicle System Dynamics, Vol. 44, Supplement, 341-348.

[8]. REN, Z., SUN, S. and ZHAI, W., 2005. Study on lateral dynamic characteristics of vehicle/turnout system. Vehicle System Dynamics, Vol. 43, No. 4, April 2005, $285-303$.

[9]. SHU, X., WILSON, N., SASAOKA, C. and ELKINS, J., 2006. Development of a real-time wheel/rail contact model in NUCARS and application to diamond crossing and turnout design simulations. Vehicle System Dynamics, Vol. 44, Supplement, 251-260.

[10]. Andersson C. and Dahlberg T., 1998. Wheel/rail Impacts at a Railway Turnout Crossing. Proceedings of the I MECH E, Part F, Journal of Rail and Rapid Transit, Vol. 212, No. 2, 1998 , 123-134(12).

[11]. Enblom, R., 2009. Deterioration mechanisms in the wheel-rail interface with focus on wear prediction: a literature review, Vehicle System Dynamics, Jan. 2009, 1-40.

[12]. Ansaria, M., Hazratib, I.A., Esmailzadeha, E. and Azadi, S., 2008. Wear rate estimation of train wheels using dynamic simulations and field measurements, Vehicle System Dynamics Vol. 46, No. 8 , August 2008, 739-759

[13]. Rosenbergera, M., Dietmaierb, P., Payera, J. and Sixc, K., 2008. The influence of the wheelsets' relative kinematics of railway vehicles on wheel/rail wear in curved track, Vehicle System Dynamics, Vol. 46, Supplement, 2008, 403-414 


\section{Appendix I - Wagon Data}

\begin{tabular}{|c|c|c|c|c|c|c|c|}
\hline \multirow[t]{2}{*}{ Component } & \multirow{2}{*}{$\frac{\text { Mass[kg] }}{\text { m }}$} & \multicolumn{3}{|c|}{ Mass Moment of Inertia $\left[\mathrm{kgm}^{2}\right]$} & \multicolumn{3}{|c|}{$\begin{array}{l}\text { Mass Centre Coordinates } \\
{\left[\begin{array}{l}{[\mathrm{m}]} \\
\end{array}\right.}\end{array}$} \\
\hline & & Ixx & Iyy & Izz & $\mathbf{X}$ & $\mathbf{Y}$ & $\mathrm{Z}$ \\
\hline \multicolumn{8}{|l|}{ Wagon } \\
\hline Empty & 9000 & $9382.8^{*}$ & $104226.1^{*}$ & $104983.3^{*}$ & -8.344 & 0 & $0.8^{*}$ \\
\hline Loaded & 74000 & $77147.5^{*}$ & $856970.4^{*}$ & $863196.2^{*}$ & -8.344 & 0 & $1.79 *$ \\
\hline \multicolumn{8}{|l|}{ Bogie 1} \\
\hline Wheelset 1 & 1087.5 & $322.7^{*}$ & $85.2^{*}$ & $322.7^{*}$ & 0 & 0 & 0.46 \\
\hline Wheelset 2 & 1087.5 & $322.7^{*}$ & $85.2^{*}$ & $322.7 *$ & -1.753 & 0 & 0.46 \\
\hline Sideframe $1 \mathrm{r}$ & $715.4^{*}$ & $116.6^{*}$ & $182.5^{*}$ & $161.5^{*}$ & -0.8765 & $-1.093^{*}$ & $0.51^{*}$ \\
\hline Sideframe 11 & $715.4^{*}$ & $116.6^{*}$ & $182.5^{*}$ & $161.5^{*}$ & -0.8765 & $1.093^{*}$ & $0.51 *$ \\
\hline Bolster 1 & $894.2 *$ & $324.1 *$ & $32.7 *$ & $186.9^{*}$ & -0.8765 & 0 & $0.52^{*}$ \\
\hline \multicolumn{8}{|l|}{ Bogie 2} \\
\hline Wheelset 3 & 1087.5 & $322.7 *$ & $85.2^{*}$ & $322.7 *$ & -14.935 & 0 & 0.46 \\
\hline Wheelset 4 & 1087.5 & $322.7^{*}$ & $85.2^{*}$ & $322.7^{*}$ & -16.688 & 0 & 0.46 \\
\hline Sideframe $2 r$ & $715.4^{*}$ & $116.6^{*}$ & $182.5^{*}$ & $161.5^{*}$ & -15.812 & $-1.093^{*}$ & $0.51 *$ \\
\hline Sideframe 2l & $715.4^{*}$ & $116.6^{*}$ & $182.5^{*}$ & $161.5^{*}$ & -15.812 & $1.093^{*}$ & $0.51^{*}$ \\
\hline Bolster 2 & $894.2^{*}$ & $324.1^{*}$ & $32.7^{*}$ & $186.9^{*}$ & -15.812 & 0 & $0.52 *$ \\
\hline
\end{tabular}

$*$ Assumed Values

The secondary suspension:

1. Friction wedge spring is $270 \mathrm{kN} / \mathrm{m}$ with preload of $18.03 \mathrm{kN}$.

2. The springs are selected based on the available information: 7 outer springs each with the rate of 392.3 $\mathrm{kN} / \mathrm{m}$ and 3 inner springs each with the rate of $196.3 \mathrm{kN} / \mathrm{m}$. Therefore, the total rate of $2746.1 \mathrm{kN} / \mathrm{m}$ is applied. The vertical natural frequency of loaded wagon car body is $f=1 / 2 \pi \times\left(4 \times 2746.1 \times 10^{3}\right)$ $(83000+2 \times 496))^{0.5}=1.82 \mathrm{~Hz}$. 